\title{
Model-centric Distribution Automation: Capacity, Reliability, and Efficiency
}

\author{
Ahmet Onen, ${ }^{1}$ Jaesung Jung, ${ }^{2}$ Murat Dilek, ${ }^{3}$ Danling Cheng, ${ }^{3}$ Robert P. Broadwater, ${ }^{4}$ \\ Charlie Scirbona, ${ }^{5}$ George Cocks, ${ }^{5}$ Stephanie Hamilton, ${ }^{6}$ and Xiaoyu Wang ${ }^{6}$ \\ ${ }^{1}$ Department of Electrical and Electronics Engineering, Abdullah Gul University, Kayseri, Turkey \\ ${ }^{2}$ Division of Energy Systems Research, Ajou University, Suwon, Korea \\ ${ }^{3}$ Electrical Distribution Design, Inc., Blacksburg, Virginia, USA \\ ${ }^{4}$ Department of Electrical and Computer Engineering, Virginia Polytechnic Institute and State University, Blacksburg, Virgina, \\ USA \\ ${ }^{5}$ Orange and Rockland Electric Utility Inc., Spring Valley, New York, USA \\ ${ }^{6}$ Brookhaven National Laboratory, Updon, New York, USA
}

\section{CONTENTS}

1. Introduction

2. DA and System Efficiency, Reliability, and Capacity: Design and Analysis

3. Simulation and Discussions

4. Conclusions

Funding

References
Keywords: distribution automation, Monte Carlo simulation, coordinated control, power system reliability, power system efficiency, power system capacity

Address correspondence to Dr. Ahmet Onen, Barbaros Mahallesi, Erkilet Bulvari, Department of Electrical and Electronics Engineering, Abdullah Gul University, Kayseri 38080, Turkey. E-mail: ahmet.onen@agu.edu.tr

Color versions of one or more of the figures in the article can be found online at www.tandfonline.com/uemp.

\begin{abstract}
A series of analyses along with field validations that evaluate efficiency, reliability, and capacity improvements of modelcentric distribution automation are presented. With model-centric distribution automation, the same model is used from design to real-time control calculations. A 14-feeder system with 7 substations is considered. The analyses involve hourly time-varying loads and annual load growth factors. Phase balancing and capacitor redesign modifications are used to better prepare the system for distribution automation, where the designs are performed considering time-varying loads. Coordinated control of load tap changing transformers, line regulators, and switched capacitor banks is considered. In evaluating distribution automation versus traditional system design and operation, quasi-steady-state power flow analysis is used. In evaluating distribution automation performance for substation transformer failures, reconfiguration for restoration analysis is performed. In evaluating distribution automation for storm conditions, Monte Carlo simulations coupled with reconfiguration for restoration calculations are used. The evaluations demonstrate that model-centric distribution automation has positive effects on system efficiency, capacity, and reliability.
\end{abstract}

\section{INTRODUCTION}

Distribution automation (DA) that uses existing system capacity more effectively, results in improved system efficiency, maintains system reliability, and requires less financial investment is desirable. To these ends, two types of automation are considered: automated switches [1] and coordinated control [2].

DA design and the control calculations that run as part of DA all use the same root model, with the goal that this root model may be used to solve all analysis problems. This is referred to herein as a model-centric approach to DA. With the 
model-centric approach, the same root model is used across all functions - planning, design, training, real-time analysis, and real-time control. The model is built and maintained from many sources of data, including the geographical information system, customer information system, load research statistics, outage management system, weather data, supervisory control and data acquisition (SCADA) historian, and SCADA interfaces.

Many experts throughout the organization contribute to the same model, and as the model is used more and more, the integrity of the data associated with the model improve. The present model represents a 14-feeder system with 7 substation transformers. The base year model contains 2148 distribution transformers and 21,991 customers, where all load measurements of each individual customer are included in the analysis. The 14 -feeder system represents approximately $5 \%$ of the utility's entire system and is representative of the entire system. A pilot system of this size is believed necessary to evaluate the true effectiveness of the automated switches.

For both design and control calculations, the calculations that run on the model make use of a year's worth of customer load data, where load estimates for a given hour and day of the year rely on load research statistics [3, 4]. The control calculations also make use of SCADA measurements, including start-of-feeder measurements, automated switch and control device measurements, fault indicator measurements, and fault current measurements.

Advanced algorithms with analysis automation are helpful to evaluate DA designs. Algorithms used here include hourly load analysis for a 10-year period involving customer load growth assumptions, reconfiguration for restoration with either manual or automated switches, and Monte Carlo simulation [5] analysis of the system under storm conditions. The overall analysis involves millions of power flow runs, and automation of the analysis process is a must.

To better prepare the 14-feeder system for DA, phase balancing and capacitor design are performed [6]. Both designs were performed for and evaluated against the time-varying load. Phase balancing is performed to provide a more balanced capacity across the phases for use by the automated switching. The capacitor design is performed to provide a more controllable system for use by the coordinated control. As will be shown, both of these design efforts resulted in a more efficient system that provides increased capacity and controllability, where the capacity increases help reliability due to rapid reconfiguration.

Design against the time-varying load [7] is very important to the results presented. Design for just peak load results in a less efficient and less controllable system that provides less balanced capacity and less total capacity.
SCADA data were used to validate the phase balanced and capacitor design changes, where field measurements were gathered prior to the implementation of the designs, and again, field measurements were collected following the field implementation. Comparing the field measurements before and after the implementation of the designs validates the value of the time-varying designs and also helps to validate the model used for the control calculations involving reconfiguration and coordinated control.

Sixty-three automated SCADA switches were installed in the 14-feeder system and placed under model-based control. The intelligence for the automated switches comes from the model-centric calculations. Because of this, it is possible to use inexpensive automated switches that do not require field programming. Substation contingency analysis that makes use of a real-time reconfiguration for a restoration algorithm shows that building a new substation can be delayed if the automated switches are installed. That is, with the forecasted load growth, the required reliability criteria could be met either with automated switches or with a new substation.

Analysis of 10 years' worth of storm data revealed that storms that affect the system could be categorized into six storm types [8]. Monte Carlo simulations that analyze the system under these six types of storm conditions and which make use of a real-time reconfiguration for a restoration algorithm are used in evaluating the automated switches. For a selected storm type, the Monte Carlo simulations considered up to 6000 individual storm simulations, where storm response is compared with and without the automated switches. Results from this analysis shows that with automated switches, the storm response could be shortened for all six types of storms. Thus, customer power is restored quicker, and at the same time, the storm response costs less.

The authors in [9] addressed the optimum selection of upgrade automation in a distribution network and its effect on reliability. In [10], an autonomous regional active network management system (AuRA-NMS) technique was applied for operational benefit existing especially of renewable resources. The authors of [11] offered an advanced power distribution system that can handle switching configuration to minimize losses. In [12], decentralized reactive flow control was used to help in the realization of advanced DA by optimally controlling the switched capacitors of the system to maintain acceptable voltage profile and minimize system losses. None of these works in the literature investigated the impact of a modelcentric approach, nor did they consider the DA benefits of a single model that can provide an efficient, reliable system with cost benefits.

In the work here, detailed analysis is used to evaluate the effects of smart grid investments on system efficiency, relia- 
bility, and capacity Also, field validation results are provided to support the correctness of the analysis.

With the model-centric approach, the coordinated control calculations use the same model as the automated switching analysis. The coordinated control has three modes of control: (1) conservation voltage reduction (CVR), (2) optimum feeder efficiency, and (3) maximum feeder capacity.

This article is organized as follows. The effects of DA on efficiency, reliability, and capacity are discussed in Section 2. The results of the studies, along with field validations, are presented in Section 3. Finally conclusions are presented in Section 4.

\section{DA AND SYSTEM EFFICIENCY, RELIABILITY, AND CAPACITY: DESIGN AND ANALYSIS}

This section investigates how DA preparatory actions and DA itself affect efficiency, reliability, and capacity. Analyses used in the evaluations are described. Results from the analysis will be described in the next section.

\subsection{Efficiency}

System efficiency is affected by phase balancing, capacitor redesign, and coordinated control.

\subsubsection{Phase Balancing.}

Phase balancing involves moving a lateral from one phase to another, in effect moving load around among the phases and balancing phase current flows [13]. Phase balancing over the time-varying load is considered as preparatory to DA. Balanced loading across the phases provides an evenly distributed capacity with which the reconfiguration can work. Furthermore, the balancing reduces losses and improves system efficiency, releasing even more capacity that may be used to meet reliability requirements during contingencies.

The phase balancing algorithm used here prioritizes the phase moves, with the highest priority phase move providing the greatest reduction in losses over the time-varying load, the next highest priority phase move providing the next greatest reduction in losses, and so forth. Typically, even with feeders that have over 200 single-phase laterals, three phase moves are sufficient to get more than $90 \%$ of the possible loss reduction.

\subsubsection{Capacitor Redesign.}

Capacitor redesign is also considered as preparatory to DA. The term "redesign" is used because the existing system already had capacitors installed, but the existing capacitors had been designed for peak load conditions [14]. Figure 1 shows a feeder power factor plotted against hour of the year where the capacitors were designed for the summer peak load condition.

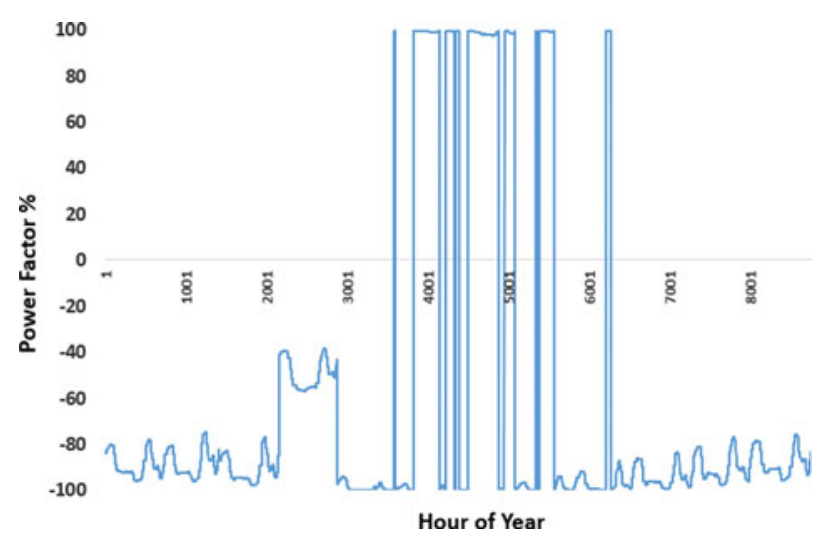

FIGURE 1. Feeder power factor resulting from summer peak design, where a negative percentage indicates a leading power factor.

Note that the feeder operates close to unity power factor much of the time during summer hours. However, the power factor often goes leading, resulting in inefficient operation. Designing against summer, winter, fall, and spring conditions can result in overall improved operations. Note that phase balancing is performed before the capacitor redesign, since it often affects capacitor redesign.

\subsubsection{Coordinated Control.}

Coordinated control of load tap changing transformers, switched capacitors, and voltage regulators can improve feeder efficiency [15]. Here the model-centric control algorithms run in a hierarchical control architecture, illustrated in Figure 2, where some of the local controllers have communications and run under coordinated control, and some of the local controllers operate by relying only on local measurements. In the architecture, the model-centric control calculations are performed at the higher hierarchical level, where measurements from throughout the system are used in performing the calculations. The model-centric control layer updates local controller set-points throughout the day to improve performance. If there

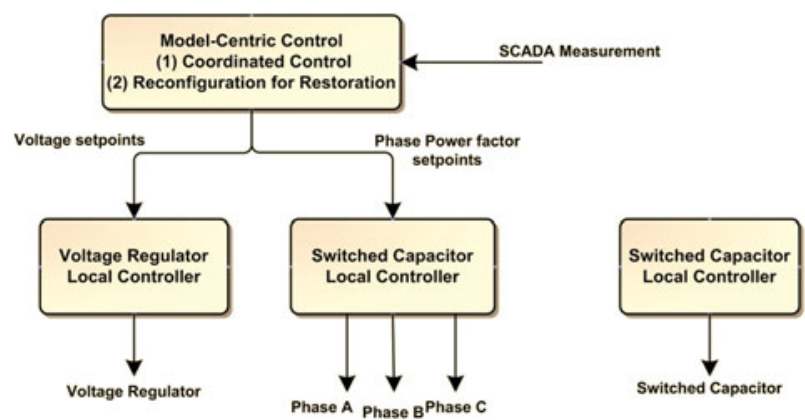

FIGURE 2. Hierarchical control architecture, where some local controllers run under coordinated control and some local controllers run with just local measurements. 


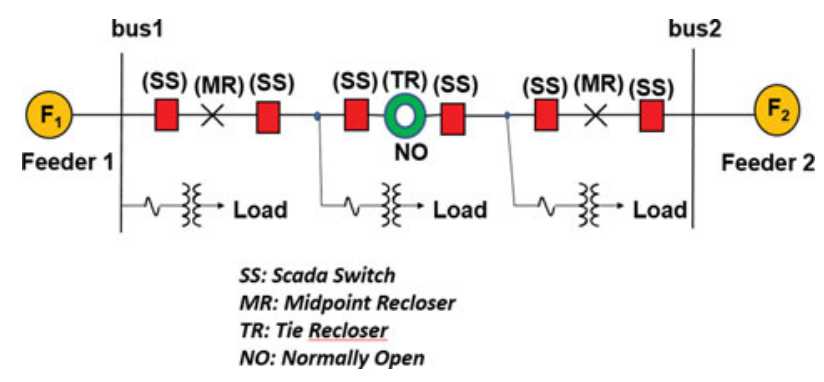

FIGURE 3. Representative automated switches design for two feeders.

are no communications to a local controller, the model-centric calculations will simulate the expected actions of the local controller in calculating what the other controllers should do. If communications are lost, then all local controllers continue to work with the last received set-point, as long as no system constraint violations occur. However, as long as the communications are working, the coordinated control can make better decisions than local controllers operating independently with limited knowledge of the system [2].

A major benefit of model-based, coordinated control is the ability to switch control objectives; that is, coordinated control can be used to achieve minimum losses on the distribution feeder, or it can be used to implement CVR, or it can be used to achieve maximum capacity under heavily loaded conditions [16]. Another benefit of coordinated control is a reduction of controller motion over local control [17]. Furthermore, as new challenges emerge, the hierarchical model-based control provides flexibility to deal with emerging challenges in a costeffective manner.

\subsection{Reliability}

There are 63 automated SCADA switches installed in the 14feeder system. Figure 3 illustrates the automated switch design for two of the feeders, where each feeder has a midpoint recloser and three SCADA or automated switches. There is a tie recloser between the two feeders. The midpoint recloser, automated switches, and tie recloser are under the control of the model-based reconfiguration for the restoration algorithm.
Thus, for the two-feeder system shown, there are nine sectionalizing devices under model-centric control. As will be shown, this automation can have a significant effect on the reliability of the system during both storms and contingencies.

\subsubsection{Storm Restoration.}

A Monte Carlo simulation is used to evaluate reliability benefits available from automated switching during storm restoration. The storm simulation consists of two basic parts that are iterated as the storm simulation progresses. In the first part, the Monte Carlo simulation fails and repairs components (i.e., based upon component-type storm failure and repair rates) as the storm progresses $[18,19]$. In the second part of the storm simulation, failures that have just occurred are isolated, and switching operations are used to restore power as much as possible prior to completing the repairs [20]. In one storm simulation, automated switches are not included in the model, and only manual switching is used [21]. In a second storm simulation, automated switches are included in the model, and only automated switches are used in the restoration of power. Comparisons of the performance of the manually operated system versus the automated system are then performed.

Table 1 shows the different storm types used in the storm simulations [8]. For each storm type shown in Table 1, two Monte Carlo simulations are performed: one with just manual switching operations and one where automatic switches have been added to the system and are used in the storm response.

\subsubsection{Substation Transformer Contingencies.}

Automated switches do not increase the inherent capacity of the system, but they do provide more rapid access to existing capacity, which can help maintain reliability requirements with load growth.

Details of the substation are shown in Fig. 4. Efficiency, capacity, and reliability benefits that derive from the smart grid investments are illustrated in the flow chart shown in Fig. 5. The substation of interest is indicated by the star shown in Fig. 6. The substation has eight feeders. Within the substa-

\begin{tabular}{l|ccc} 
Storm types and descriptions & $T$ range $\left({ }^{\circ} \mathrm{F}\right)$ & Wind speed (mph) & Average length (hr) \\
\hline H: high temperature, no strong wind & $\operatorname{Max} T>80$ & $W S \leq 20$ & WS $>20$ \\
HS: high temperature, strong wind & $\operatorname{Max} T>80$ & $W S \leq 20$ & 84 \\
L: low temperature, no strong wind & $\operatorname{Min} T<32$ & $W S>20$ & 55 \\
LS: low temperature, strong wind & $\operatorname{Min} T<32$ & $W S \leq 20$ & 146 \\
M: moderate temperature, no strong wind & $\operatorname{Max} T \leq 80, \operatorname{Min} T \geq 32$ & $W S>20$ & 35 \\
MS: moderate temperature, strong wind & $\operatorname{Max} T \leq 80, \operatorname{Min} T \geq 32$ &
\end{tabular}

$\operatorname{Max} T$ : maximum temperature; MinT: minimum temperature; $W S$ : wind speed 


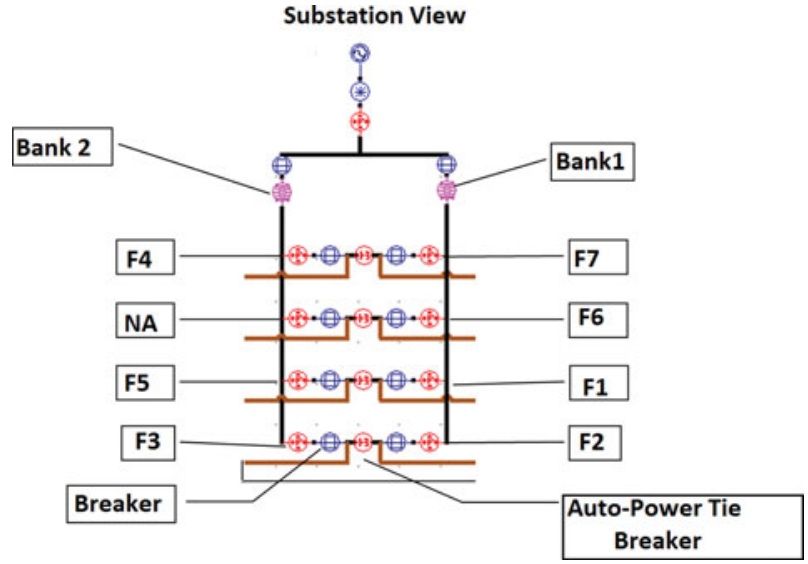

FIGURE 4. Substation considered in substation deferral study, where location of substation is indicated as pilot substation in Figure 6.

tion there are two transformer banks: bank 1 and bank 2 . The normal rating for each bank is 42 MVA.

Access to the existing capacity of the system shown in Figure 6 can be improved with automated switches, which can help with meeting reliability requirements associated with contingencies. Contingencies considered here are failures of

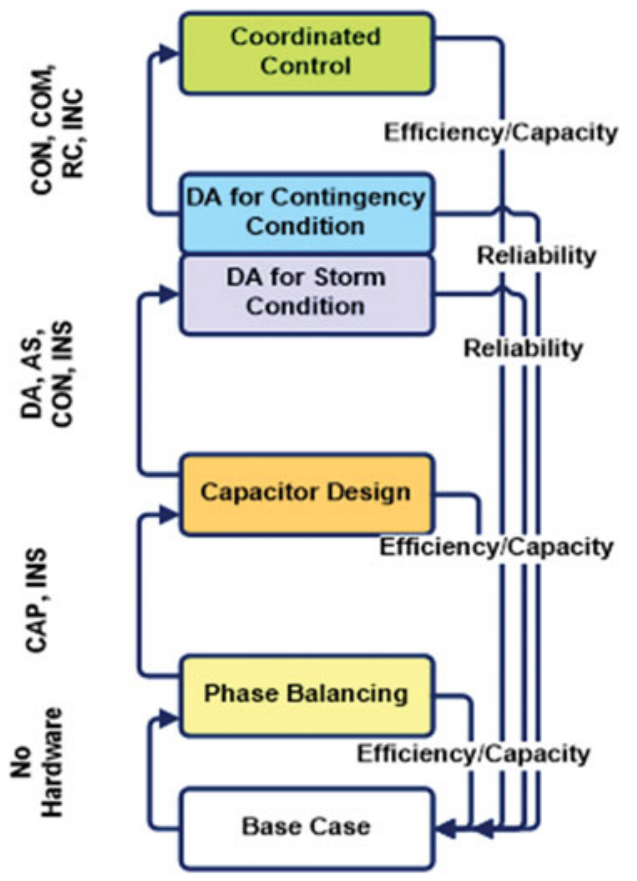

DA : Distribution Automation

AS: Automated Switches

RC: Remote Control

CON: Controller

COM: Communication

INS: Installation

CAP: Capacitors

FIGURE 5. Smart grid analysis flowchart.

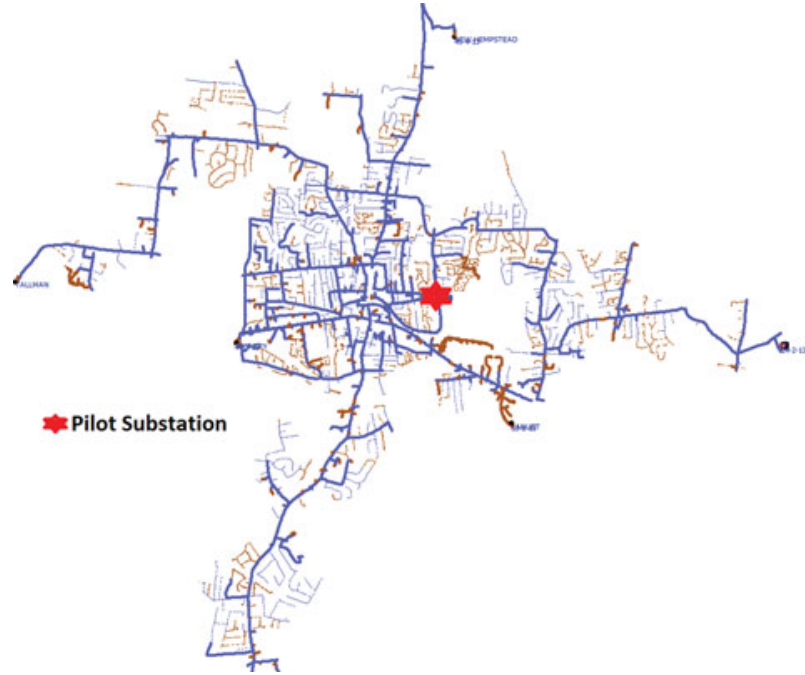

FIGURE 6. Fourteen-feeder system with substation of interest highlighted.

substation transformers. For substation transformer failures, there is a limit of $60,000 \mathrm{hr}$ of customer downtime during the first $24 \mathrm{hr}$ of interruption. When a substation transformer fails and this 60,000 -hr limit is exceeded, then the system must be upgraded to bring the hours of downtime below 60,000 [18]. Because each individual customer in the 14-feeder system is modeled, hours of downtime can be calculated by the Monte Carlo simulation by counting the number of customers without power during each hour of the storm simulation.

When the substation transformer failure downtime limit is exceeded, the classical solution is to invest in adding a new substation. However, adding automated switches provides more rapid access to existing capacity by moving the load around among feeders, and this provides an alternative to the classical solution for meeting reliability requirements with load growth.

\subsection{Capacity Evaluation}

Similar to system efficiency, system capacity is affected by phase balancing, capacitor redesign, and coordinated control. Three-phase capacity is limited by the highest loaded phase. Phase balancing helps to increase the usability of the threephase capacity of the system, presenting a more balanced threephase system for use by reconfiguration for restoration. Better capacitor redesign also helps to increase system capacity. It is important that the capacity increases be maintained over the time-varying load since the reconfiguration needs as much capacity as possible for picking up load at all points in time.

The coordinated control considered here has a maximum capacity mode [15]. Coordinated control makes better use of system capacity than local control, especially during reconfiguration of the system. This is because the coordinated control immediately responds to system reconfigurations by recalcu- 


\begin{tabular}{|c|c|}
\hline Component type & $\begin{array}{l}\text { Numbers for } \\
\text { 14-feeder model }\end{array}$ \\
\hline Primary overhead line & 6027 \\
\hline Overhead line cutout & 828 \\
\hline Overhead distribution transformer & 2148 \\
\hline Overhead step transformer & 14 \\
\hline Voltage regulator & 1 \\
\hline Recloser & 78 \\
\hline Switched capacitor & 12 \\
\hline Fixed capacitor & 16 \\
\hline Gang operated air breaker (GOAB) & 45 \\
\hline Disconnect switches & 286 \\
\hline Underground cable (primary) & 2917 \\
\hline Underground distribution transformer & 1292 \\
\hline Underground switches & 32 \\
\hline Buses (transmission/distribution) & 8 \\
\hline Transformer (transmission/distribution) & 15 \\
\hline Breaker/switch (transmission/distribution) & 8 \\
\hline
\end{tabular}

TABLE 2. Component types and numbers

lating local controller set points. It should be noted that updates to local set-points are not only needed because of loads being switched from one feeder to another, but are especially needed when a controller itself is switched from one feeder to another.

Quasi-steady-state power flow analysis is used to evaluate capacity increases in the next section.

\subsection{Smart Grid Evaluations and Benefits}

Efficiency, capacity, and reliability benefits that derive from the smart grid investments are illustrated in the flowchart shown in Figure 5. A series of investments are evaluated here, where the performance of an investment may depend upon previous investments. The first investments considered are in phase balancing and capacitor replacement, and these investments affect the efficiency and capacity of the system. These investments

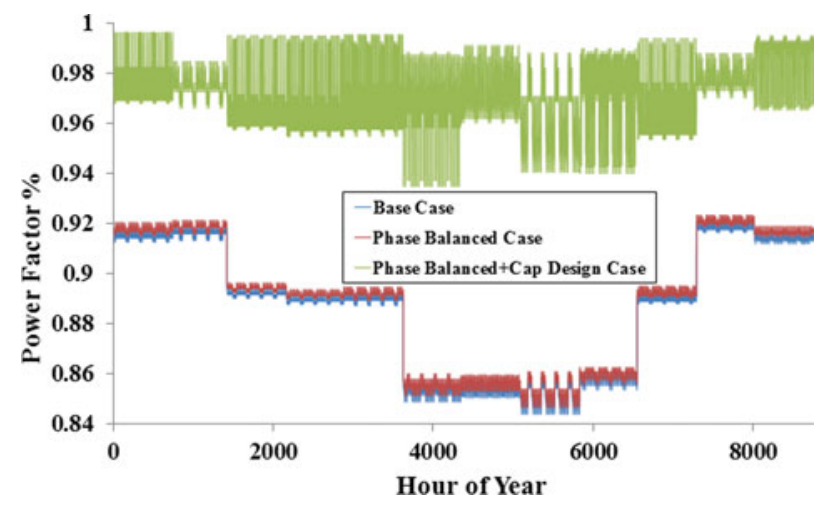

FIGURE 7. Overall 14-feeder power factor for base case, phase-balanced case, and capacitor design case across 8760 hours in year. by themselves are not thought of as smart grid investments, but these investments will leverage the performance of the smart grid investments considered next. Phase balancing is considered before capacitor replacement, because phase balancing can affect the size and location of the capacitors. A major benefit that derives from these investments is reduced system losses.

The next investment considered is coordinated control, where the performance of the coordinated control is improved with a phase-balanced system with controllable capacitors in good locations; that is, the performance of coordinated control depends upon the previous work in phase balancing and capacitor replacement. Coordinated control affects the efficiency and capacity of the system.

The final investment considered is in automated switching. The performance of this investment is improved due to the investment in coordinated control. This is because when the system configuration changes, coordinated control will operate controllable devices to achieve the best efficiency and more system capacity if needed.

The investment in automated switching affects system reliability. The improved reliability that comes from the automated switching is due to more rapid utilization of existing system capacity to restore power loss. Here the reliability evaluation consists of two parts: improvements in major storm response and improvements in contingency response. Due to the automated switching, much larger investments in new substations can be delayed for significant periods of time, and expensive operations that occur during storm response are shortened.

In summary, efficiency, reliability, and capacity are evaluated in the smart grid investments considered here.

\section{SIMULATION AND DISCUSSIONS}

The system used for the evaluations is shown in Figure 6. This system consists of 14 feeders supplied by 7 different substation transformers. The location of the substation of interest for contingency evaluations is shown in Figure 6.

The system has 7 load tap changers, 16 fixed shunt capacitors, 12 switched shunt capacitors, and 1 voltage regulator. The voltage regulator has individual phase controls. Table 2 presents information related to substations, feeders, and components in the system, including control devices.

The load on the system consists of residential, industrial, and small commercial customers, totaling 21,991 customers served by 2148 overhead distribution transformers. Each customer and its load measurement are modeled.

\subsection{Efficiency Evaluation Results}

\subsubsection{Phase Balancing.}

Phase balancing that takes into account time-varying loads was performed on the 14 feeders of Figure 6. A series of 8760 


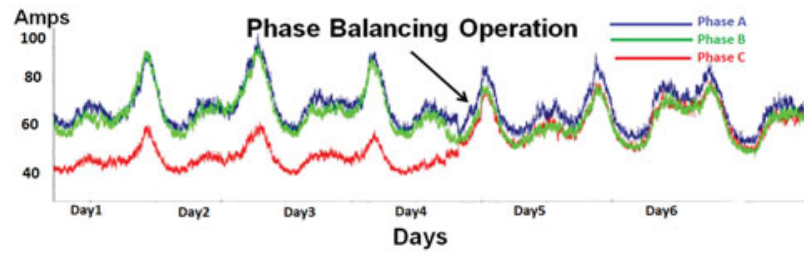

FIGURE 8. Representative phase $A$ (red), $B$ (blue), and $C$ (green) current measurements at start of feeder for phase balancing validation, where time of phase balancing occurred late on day 3.

quasi-steady state power flow runs (i.e., one for each hour of the year) were then made on the test system of Figure 6 prior to phase balancing, then a series of 8760 power flow runs was made on the phase balanced system.

Figure 7 compares the system power factor that results from the two quasi-steady-state power flow runs, where it may be noted that the phase balancing design has a slightly higher efficiency across all time points than the base case. It should be noted that the feeders considered here are very short, around 5 miles long. Much longer feeders would typically result in larger efficiency improvements from phase balancing.

Figure 8 shows a field validation of the phase balancing operations [22]. Start-of-feeder phase current measurements were recorded by a SCADA historian, and the current measurements are compared prior to and after the phase balancing operation. The plot covers several days of operation and shows how the phase balancing operation affects the phase current flows. From the plot, it may be seen that phase $A$ current (red curve in Figure 8) is getting back together with other phase currents at the time when the phase balancing occurred.

\subsubsection{Capacitor design.}

Capacitor design is often performed for a single time point, the peak. This can result in inefficient operation of the feeder over much of the year, as illustrated in Figure 1.

Figure 9 shows how capacitor design performed for the time-varying load can provide excellent efficiency throughout the year. By comparing Figures 1 and 9, it may be seen that there are significant efficiency improvements from the timevarying design versus peak load only design.

Figure 7 shows the time variation of the 14-feeder system power factor following the capacitor redesign. It may be seen that there is a significant improvement in the system power factor following the capacitor redesign.

Substation power factor measurements were made prior to the capacitor redesign, and again following the field implementation of the capacitor redesign. Table 3 shows three such measurements. From the measurements it may be seen that the power factor measured at the transformer banks in the shown substations increased following the redesign.

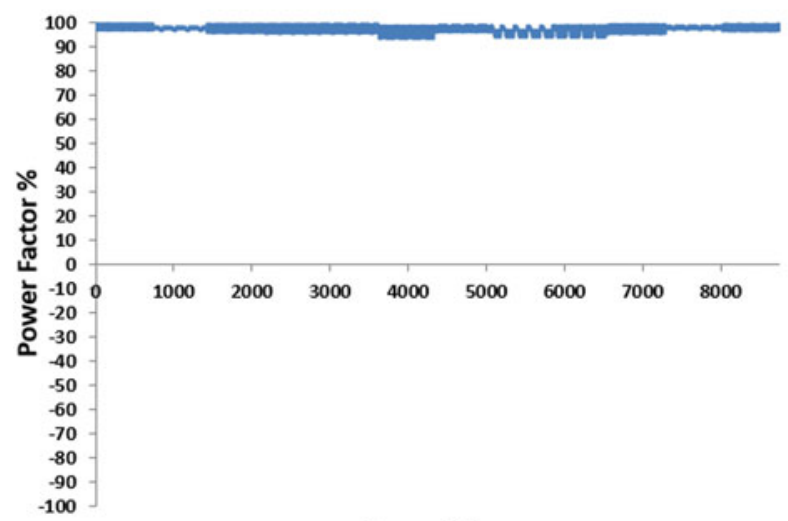

Hour of Year

FIGURE 9. Feeder power factor with time-varying capacitor design.

\begin{tabular}{l|ccc} 
Substation & $\begin{array}{c}\text { Transformer } \\
\text { bank }\end{array}$ & $\begin{array}{c}\text { Power factor } \\
\text { before design }\end{array}$ & $\begin{array}{c}\text { Power factor } \\
\text { after design }\end{array}$ \\
\hline A & 1 & 0.9620 & 0.9702 \\
A & 2 & 0.9347 & 0.9950 \\
B & 3 & 0.9759 & 0.9865
\end{tabular}

TABLE 3. Validation of capacitor design

\subsubsection{Coordinated Control.}

The coordinated control solution for minimum system losses (efficiency mode) of the 14-feeder system is compared with the coordinated control for the CVR mode solution, and results are shown in Table 4 . When the coordinated control works to minimize the system losses, the system voltages run higher (to minimize losses in power transmission) than when the coordinated control works to minimize the operating voltage (while still maintaining the voltage above the lower limit of 114 volts) to reduce the energy drawn by the loads.

The results shown in Table 4 are based upon using a 1\% load-voltage dependency factor, where a $1 \%$ reduction in voltage results in a $1 \%$ reduction in current. An interesting observation from Table 4 is that the CVR mode results in a greater transmission loss reduction, even though the feeder is running at a lower voltage. This transmission loss reduction is attributed to the smaller loads being supplied in the CVR mode. Thus, raising the voltage, and decreasing the current flow, results in reducing transmission system losses with a constant power load but not necessarily with a voltage-dependent load.

\subsection{Reliability Evaluation Results}

\subsubsection{Storm Restoration Evaluation Case.}

In the Monte Carlo simulation, it is assumed that automated switches can be operated instantaneously. For manual switch operations and for a given failure, it is assumed that it takes $1 \mathrm{hr}$ 


\begin{tabular}{l|lcc} 
& & CVR mode & Efficiency mode \\
\hline Manual model & MWHr supplied & $376,099.30$ & $376,099.30$ \\
Automated & Total losses (MWH) & 5449.795 & 5449.796 \\
model & MWHr supplied & $365,177.04$ & $373,240.30$ \\
& & & 5130 \\
Comparison & Total losses (MWH) & 5134.95 & 2859.00 \\
& Energy supplied reduction (MWHr) & $10,922.26$ & 267.42 \\
& Loss reduction (MWH) & 314.85 & 0.76 \\
& Energy supplied reduction (\%) & 2.90 & 4.91
\end{tabular}

TABLE 4. Comparison of coordinated control modes

to operate the first manual switch, and each additional manual switch operation associated with the failure is assumed to take $15 \mathrm{~min}$. These manual switch operation times were obtained from utility operating experience and statistics.

Table 5 compares the results of the automated system (i.e., system with 63 SCADA switches) with the system with manually operated switches for each of the storm types. In Table 5, the number of hours that crews spend operating manual switches for each storm type is shown for the manual system. The crews do not spend any time operating switches in the automated system.

Table 5 also shows the total customer outage hours for both systems for each type of storm. It can be seen from the last column in Table 5 that the automated system provides significant improvements in system average interruption duration index (SAIDI) over the manually operated system.

\subsubsection{Contingency Evaluation Case.}

A comparison of customer downtimes that result from transformer bank failures is now considered. For the projected load growth, the customer downtime for the system with manually operated switches will be compared to the system with automated switches, where the automated switch design is illustrated in Figure 3. Figures 10 and 11 illustrate the results of the comparison for banks 1 and 2, respectively, where the transformer banks of interest are shown in Figure 4.

The red lines in Figures 10 and 11 indicate the limit of $60,000 \mathrm{hr}$ of customer downtime. The green lines in Figures 10 and 11 represent the hours of customer downtime as a function of year for the manually switched system, where load growth causes the customer downtime to increase from one year to the next. The blue line is for the system with automated switches. As seen from the figures, with the manually operated sys-

\begin{tabular}{|c|c|c|c|c|c|}
\hline \multirow[b]{2}{*}{ Type of storm } & \multirow[b]{2}{*}{$\begin{array}{l}\text { Average number of } \\
\text { failures per storm }\end{array}$} & \multicolumn{2}{|c|}{ Manually switched system } & \multirow{2}{*}{$\begin{array}{c}\begin{array}{c}\text { Automatically } \\
\text { switched system }\end{array} \\
\begin{array}{c}\text { Total customer } \\
\text { outage hours }\end{array}\end{array}$} & \multirow[b]{2}{*}{$\begin{array}{c}\text { SAIDI improvement } \\
(\%)\end{array}$} \\
\hline & & $\begin{array}{l}\text { Device switching } \\
\text { hours }\end{array}$ & $\begin{array}{l}\text { Total customer } \\
\text { outage hours }\end{array}$ & & \\
\hline $\begin{array}{l}\text { H: high temperature, no } \\
\text { strong wind }\end{array}$ & 18 & 40 & 113,674 & 95,859 & 0.4051 \\
\hline $\begin{array}{l}\text { HS: high temperature, } \\
\text { strong wind }\end{array}$ & 96 & 213 & 874,317 & 745,988 & 2.9178 \\
\hline $\begin{array}{l}\text { M: moderate } \\
\text { temperature, no strong } \\
\text { wind }\end{array}$ & 27 & 60 & 103,662 & 60,925 & 0.9717 \\
\hline $\begin{array}{l}\text { MS: moderate } \\
\text { temperature, strong } \\
\text { wind }\end{array}$ & 74 & 168 & 531,059 & 431,580 & 2.2618 \\
\hline $\begin{array}{l}\text { L: low temperature, no } \\
\text { strong wind }\end{array}$ & 55 & 132 & 301,707 & 197,353 & 2.3727 \\
\hline $\begin{array}{l}\text { LS: low temperature, } \\
\text { strong wind }\end{array}$ & 173 & 403 & $2,812,471$ & $2,623,756$ & 4.2907 \\
\hline
\end{tabular}

TABLE 5. Customer outage times and SAIDI improvements for different types of storms 


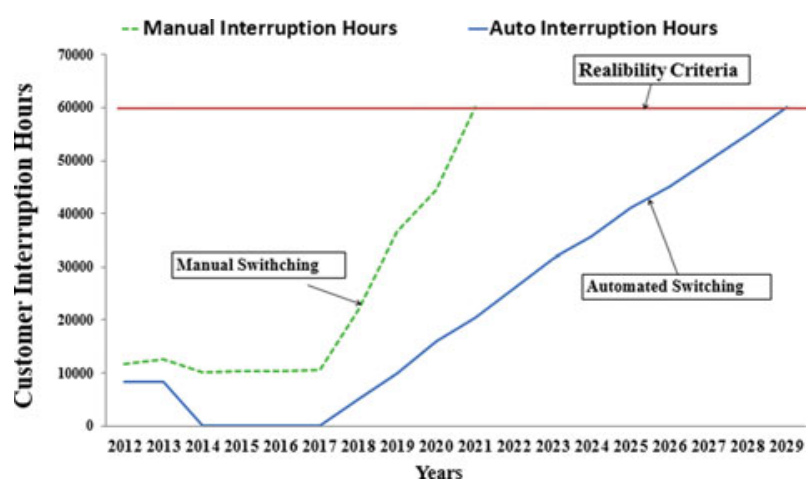

FIGURE 10. Reliability criteria comparison between manual and automated switching performance for failure of existing substation transformer bank 1 .

tem, the reliability criteria are violated in year 2021 for both transformer failures, whereas for the system with automated switches, the reliability criteria are not violated until year 2028 . Also seen in Figures 10 and 11, between years 2014 and 2017, the automated system results in approximately 10,000 fewer hours of customer downtime than the manually operated system. It may also be noted from Figure 10 that the automated system results in 100\% backup for bank 1 from 2014-2017.

Thus, the building of a new substation needed for meeting the reliability criteria can be delayed approximately 7 years with the automated system; in other words, smart grid automation can be considered as an alternative to starting the construction of and investment in a new substation.

\subsubsection{Capacity Evaluation Results.}

Figure 12 compares the system capacity for year 2017 before phase balancing and capacitor design were performed with the system capacity after phase balancing and capacitor design were performed, where system capacity is measured relative

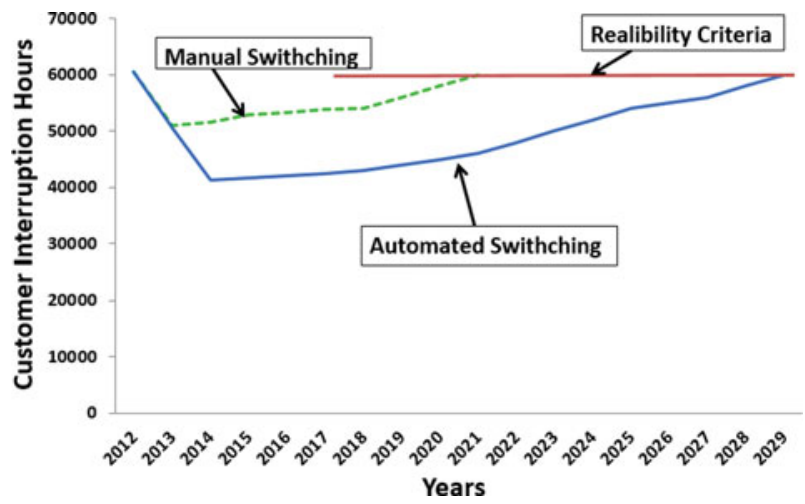

FIGURE 11. Reliability criteria comparison between manual and automated switching performance for failure of existing substation transformer bank 2 .

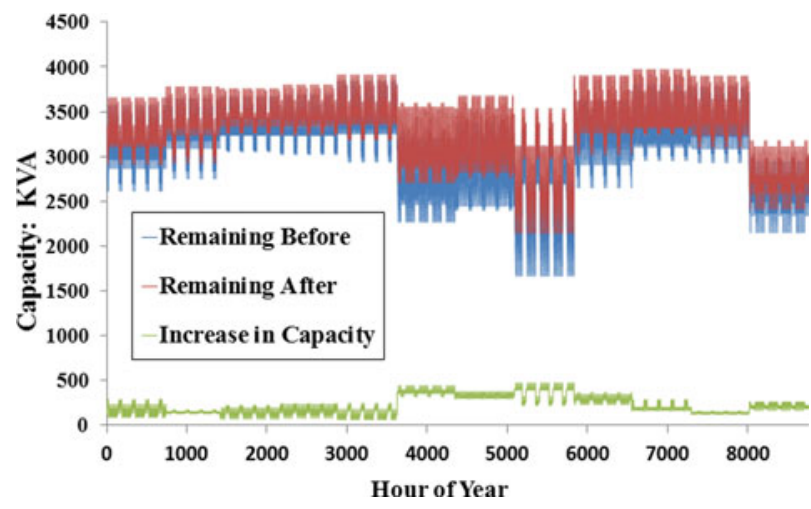

FIGURE 12. Remaining capacities and increase in capacity before and after design.

to the highest loaded phase on each feeder. This is the phase that would set the limit on the allowable size of new three-phase loads.

The green curve in Figure 12 shows the difference in remaining capacity between the system that has been phase balanced with capacitor design and the system without phase balancing and capacitor design. From Figure 12, it is interesting to note that the increase in capacity is larger during the summer months (i.e., approximately hours 3600-5760), and since this is a summer peaking system, the larger increase in capacity occurs when it is needed the most.

The summation of the increase in capacity over all 8760 hours is 1845 MVA. The average hourly increase in capacity for the system is $210 \mathrm{~kW}$. This extra capacity can be used for providing power to neighboring feeders during contingencies.

\section{CONCLUSIONS}

In the present work, a detailed model of the system that includes every customer served by the system is used for both design and real-time analysis and control, leading to a modelcentric DA system. Here the model is used to evaluate the effects of investments made in DA and their value measured in terms of system efficiency, reliability, and capacity.

In efficiency and capacity evaluations, time-varying phase balancing and capacitor designs are considered as part of the smart grid investments because they provide a more controllable system for coordinated control, and they also provide greater three-phase capacity for automated switching operations. It is demonstrated that significant improvements in efficiency can be obtained with time-varying designs versus peak designs.

It is also demonstrated that significant increases in capacity are also available from the time-varying phase balancing and 
capacitor designs. These capacity increases can provide greater opportunities to aid the automated switching operations and help improve reliability. An interesting observation from the analysis is that the capacity increases were greatest when the system load was the greatest, which is the desired result.

Coordinated control for maximum feeder efficiency is compared with coordinated control for CVR mode. An interesting result is that the CVR mode, with the lower average feeder voltage, actually results in less loss in the feeders themselves.

In reliability evaluations, automated switches are considered from two perspectives: how they can aid in restoring power more rapidly for storm restoration and how they can aid in major contingencies by providing more rapid access to system capacity. In the storms considered here, with automated switches, the field crews went directly to repairs and did not spend time operating switches. With this approach there were more customers without power while the crews were doing the repairs. This is because there were approximately 12 times more manual switches in the system than automated switches. However, the crews were able to get the power restored faster in the automated system, and this resulted in overall less downtime for the customers as compared to the manually switched system.

The reliability effects of automated switches were also considered on contingencies involving substation transformer failures. For the system considered here, it was demonstrated that reliability criteria could be met for 7 years longer with the automated system. As a result, the building of a new substation could be delayed.

For the 14-feeder system considered, the results show that DA provides very positive benefits for system efficiency, reliability, and capacity. As has been experienced in other industries, investments in system automation can lead to increased production and performance.

\section{FUNDING}

The authors would like to thank Electrical Distribution Design, Inc., Orange \& Rockland, and Brookhaven National Laboratory for providing data, funding, and technical assistance.

\section{REFERENCES}

[1] Kleppinger, D., Broadwater, R., and Scirbona, C., "Generic reconfiguration for restoration," Electr. Power Syst. Res., Vol. 80, No. 3, pp. 287-295, March 2010.

[2] Onen, A., Cheng, D., Arghandeh, R., Jung, J., Woyak, J., Dilek, M., and Broadwater, R., "Smart model-based coordinated control based on feeder losses, energy consumption, and voltage violations," Electr. Power Compon. Syst., Vol. 41, No. 16, pp. 1686-1696, August 2013.

[3] Broadwater, R., Sargent, A., Yarali, A., Shaalan, H., and Nazarko, J., "Estimating substation peaks from load research data," IEEE Trans. Power Del., Vol. 12, No. 1, pp. 451-456, January 1997.

[4] Sargent, A., Broadwater, R. P., Thompson, J., and Nazarko, J., "Estimation of diversity and KWHR-to-peak-KW factors from load research data," IEEE Trans. Power Syst., Vol. 9, No. 3, pp. 1450-1456, August 1994.

[5] Jung, J., Cho, Y., Cheng, D., Onen, A., Arghandeh, R., Dilek, M., and Broadwater, R., "Monte Carlo analysis of plug-in hybrid vehicles and distributed energy resource growth with residential energy storage in Michigan," Appl. Energy, Vol. 108, pp. 218-235, 2013.

[6] Dilek, M., Integrated Design of Electrical Distribution Systems: Phase Balancing and Phase Prediction Case Studies, Ph.D. Dissertation, Virginia Polytechnic Institute and State University, Blacksburg, VA, March 2001.

[7] Onen, A., Woyak, J., Arghandeh, R., Jung, J., Scirbona, C., and Broadwater, R. P., "Time-varying cost of loss evaluation in distribution networks using market marginal price," Int. J. Electr. Power Energy Syst., Vol. 62, pp. 712-717, June 2014.

[8] Zhu, D., Cheng, D., Broadwater, R., and Scirbona, C., "Storm modeling for prediction of power distribution system outages," Electr. Power Syst. Res., Vol. 77, No. 8, pp. 973-979, June 2007.

[9] Bouhouras, A. S., Andreou, G. T., Labridis, D. P., and Bakirtzis, A. G., "Selective automation upgrade in distribution networks towards a smarter grid," IEEE Trans. Smart Grid, Vol. 1, No. 3, pp. 278-285, December 2010.

[10] Hu, Z., and Li, F., "Cost-benefit analyses of active distribution network management, Part I: Annual benefit analysis," IEEE Trans. Smart Grid, Vol. 3, No. 3, pp. 1067-1074, September 2012.

[11] Kim, J.-C., Cho, S.-M., and Shin, H.-S., "Advanced power distribution system configuration for smart grid," IEEE Trans. Smart Grid, Vol. 4, No. 1, pp. 353-358, March 2013.

[12] Elkhatib, M. E., El Shatshat, R., and Salama, M. M. A., "Decentralized reactive power control for advanced distribution automation systems," IEEE Trans. Smart Grid, Vol. 3, No. 3, 1482-1490, September 2012.

[13] Dilek, M., Broadwater, R., Thompson, J., and Sequin, R., "Simultaneous phase balancing at substations and switches with time-varying load patterns," IEEE Trans. Power Syst., Vol. 16, No. 4, pp. 922-928, November 2001.

[14] Manglani, T., and Shishodia, Y. S., "A survey of optimal capacitor placement techniques on distribution lines to reduce losses," Int. J. Recent Res. Rev., Vol. I, pp. 1-7, March 2012.

[15] Hambrick, J., and Broadwater, R., "Configurable, hierarchical, model-based control of electrical distribution circuits," IEEE Trans. Power Syst., Vol. 26, No. 3, pp. 1072-1079, August 2011.

[16] Hambrick, J., and Broadwater, R., "Advantages of integrated system model-based control for electrical distribution system automation," Proceedings of 18th IFAC World Congress, Milano, Italy, . 28 August-2 September 2011.

[17] Jung, J., Onen, A., Arghandeh, R., and Broadwater, R. P., “Coordinated control of automated devices and photovoltaic generators for voltage rise mitigation in power distribution circuits," Renew. Energy, Vol. 66, pp. 532-540, June 2014.

[18] Billiton, R., and Li, W., Reliability Assessment of Electrical Power Systems Using Monte Carlo Methods, Springer, 2006.

[19] Cheng, D., Liang, Y., Zhu, D., and Broadwater, R. P., "Real-time power electric system modeling, assessment and reliability pre- 
diction," IEEE/PES Power Systems Conference and Exposition (PSCE '09), Seattle, 15-18 March 2009.

[20] Meliopoulos, A. P. S., Cokkinides, G., Huang, R., Farantatos, E., Choi, S., Lee, Y., and Yu, X., "Smart grid technologies for autonomous operation and control," IEEE Trans. Smart Grid, Vol. 2, No. 1, pp. 1-10, March 2011.

[21] Kleppinger, D., Prioritized Reconfiguration of Interdependent Critical Infrastructure Systems, Ph.D. Dissertation, Virginia Polytechnic Institute and State University, Blacksburg, VA, March 2009.

[22] Onen, A., Model- Based Grid Modernization Economic Evaluation Framework, Ph.D. Dissertation, Virginia Polytechnic Institute and State University, Blacksburg, VA, March 2014.

\section{BIOGRAPHIES}

Ahmet Onen received his Ph.D. from the Electrical and Computer Engineering Department at Virginia Tech. He is currently an assistant professor at Abdullah Gul University. He is a member of distributed engineering workstation (DEW) software developing team for power systems planning and operation. His research interests are distribution system reliability; storm outage and reconfiguration; distributed generation; and smart grid optimization, control, and economic analysis.

Jaesung Jung received his Ph.D. in electrical engineering at Virginia Polytechnic Institute and State University, Blacksburg. He received his M.S. from the Department of Electrical and Computer Engineering at North Carolina State University, Raleigh, in 2009. He is currently working at Brookhaven National Lab as a senior scientist. His research interests include the development and deployment of renewable and sustainable energy technologies.

Murat Dilek received his M.S. and Ph.D. in electrical engineering from Virginia Tech, Blacksburg, in 1996 and 2001, respectively. He is a senior development engineer at Electrical Distribution Design, Inc. His work involves computer-aided design and analysis of electrical power systems.

Danling Cheng holds a senior engineer/application development position at Electrical Distribution Design Inc., where she provides utility modeling solutions and application developments for planning and operations. Her specialties include customized contingency analysis, reliability evaluation, coordinate control, storm outage and reconfiguration analysis, and power system simulation model building via synchronized geographical information system (GIS) systems.
Robert P. Broadwater is a professor of power systems and software engineering at Virginia Polytechnic Institute and State University. He works in the area of generic analysis.

Charlie Scirbona has held various positions at Orange and Rockland Utilities in engineering and operations, including line supervisor, area line supervisor, superintendent of the overhead line, superintendent of transmission operations, superintendent of substation and relay operations, and manager of distribution engineering. $\mathrm{He}$ is currently a department manager of smart grid engineering and is managing the smart grid development and installation at Orange and Rockland. His technical interests include power system operation, protection, and smart grids.

George Cocks is an electrical engineer at Orange and Rockland Utilities, where he is actively working to implement advanced automation and enhanced efficiency to critical parts of the Orange and Rockland power delivery system. His work is focused on power distribution system modeling, analysis, and automation design.

Stephanie Hamilton is a smart grid R\&D manager for Brookhaven National Laboratory and has previously worked for Electric Power Research Institute (EPRI). She was in charge of distributed energy resources for Southern California Edison for over 10 years, during which time she sought and received over $\$ 4$ million in funding for RD\&D. She holds an M.S. in management, a B.S. in mechanical engineering, and a B.S. in applied psychology; she has been widely published on energy and energy-related issues. She has held a variety of ever-increasing managerial responsibilities in energy (natural gas, power, and fuels), including planning, operations, business development, consulting, and marketing and sales.

Xiaoyu Wang has been with the Sustainable Energy Technologies Department of Brookhaven National Laboratory since 2011. He received his B.Eng. and M.Eng. in electrical engineering from North China Electric Power University, Beijing, China, and his Ph.D. in electrical engineering from Nanyang Technological University, Singapore, in 1999, 2004, and 2008, respectively. His research interests include integration of renewable resources with transmission and distribution systems, energy storage systems, and relay protections. 